\title{
E. Kausalität und Adäquanz
}

Auch im Bereich der Organhaftung bedarf es eines kausalen Zusammenhangs zwischen dem sorgfaltswidrigen Verhalten und dem entstandenen Schaden ${ }^{604}$. Je nachdem, ob die Sorgfaltswidrigkeit in einem aktiven Tun oder in einer Unterlassung liegt, ist Kausalität dann zu bejahen, wenn ohne das pflichtwidrige Handeln bzw. Unterlassen der Organe kein Schaden für die Gesellschaft entstanden wäre ${ }^{605}$. Den Mitgliedern des Vorstands und des Aufsichtsrats steht es frei zu beweisen, dass jener Vermögensnachteil auch bei rechtmäßigem Alternativverhalten eingetreten wäre ${ }^{606}$.

Ebenso ist auch bei der Organhaftung die Adäquanztheorie zu berücksichtigen ${ }^{607}$. Inadäquanz ist gegeben, wenn die sorgfaltswidrige Handlung aus objektiver ex ante-Perspektive gänzlich ungeeignet war, den konkreten Schaden herbeizuführen und diese somit lediglich aufgrund außergewöhnlicher Umstände kausal für den Vermögensnachteil wurde ${ }^{608}$. In der hier geschilderten Thematik sind jedoch kaum Fälle denkbar, in denen sich die Verantwortlichen mit Erfolg auf das Fehlen jener Vorhersehbarkeit berufen können. So ist es etwa auch durchaus absehbar, dass eine negative Entwicklung des Finanzportfolios einen Liquiditätsmangel nach sich ziehen kann, welcher die Aufnahme eines kostspieligen Kredits notwendig macht.

604 Nowotny in Doralt/Nowotny/Kalss, Kommentar zum Aktiengesetz ${ }^{2}$ (2012) $\S 84$ Rz. 23; Kalss in Doralt/Nowotny/Kalss, Kommentar zum Aktiengesetz ${ }^{2}$ (2012) § 99 Rz. 44.

605 Siehe dazu allgemein: Reischauer in Rummel, Kommentar zum ABGB II $^{2}$ a (2007) § 1295 Rz. 2.

606 Siehe dazu allgemein: Reischauer in Rummel, Kommentar zum ABGB33 II/2a (2007) § 1295 Rz. 1a.

607 Nowotny in Doralt/Nowotny/Kalss, Kommentar zum Aktiengesetz ${ }^{2}$ (2012) § 84 Rz. 23; Mertens/Can in Zöllner/Noack, Kölner Kommentar zum Aktiengesetz ${ }^{3}$ (2010) Band 2/1, § 93 Rz. 55; Schlosser, Die Organhaftung der Vorstandsmitglieder der Aktiengesellschaft (2002) 110; Kalss in Doralt/Nowotny/Kalss, Kommentar zum Aktiengesetz ${ }^{2}$ (2012) § 99 Rz. 44.

608 Enneccerus/Lehmann, Lehrbuch des bürgerlichen Rechts - Recht der Schuldverhältnisse ${ }^{15}$ (1958) 66.

S. Hammerschmidt, Organverantwortlichkeit für Finanzanlagegeschäfte in der AG, 